\title{
A retextualização escrita-escrita
}

\section{Written-written retextualization ${ }^{I}$}

Dennys Dikson*

*Universidade Federal Rural de Pernambuco (UFRPE), Garanhuns, Pernambuco /

Brasil

dennys.dikson@ufrpe.br

\begin{abstract}
RESUMO: Neste ensaio, situado na Linguística Textual, rediscutimos determinadas questões presentes no processo de retextualização, especialmente quanto aos aspectos e procedimentos envolvidos na produção de um texto-fim escrito a partir de um texto-base também escrito, levando em consideração as noções forjadas e discutidas por Marcuschi. Ao apresentar um quadro teóricometodológico que foca especificamente a retextualização da fala para a escrita, o autor acaba por deixar de fora os processos envolvidos nas produções da escrita para a escrita. Tendo essa lacuna como ponto de reflexão primário, e pensando em atividades construídas por crianças em ambiente escolar, apresentamos uma discussão inicial que traz um quadro teórico-metodológico que abrange especificamente os aspectos e procedimentos envolvidos no processo de retextualização de gêneros escritos para gêneros escritos. A intenção é contribuir tanto para a melhoria do estado da arte quanto para a possibilidade de o professor/investigador possuir um caminho metodológico mais adequado no trato do retexto escrita-escrita.
\end{abstract}

PALAVRAS-CHAVE: retextualização; da escrita para a escrita; produção textual; atividade escolar.

\begin{abstract}
In this study of the field of Text Linguistics, we discuss certain issues present in the process of retextualization, especially as to the aspects and procedures involved in the production of a written target-text based on an also written source-text, considering notions coined and discussed by Marcuschi. By presenting a theoretical-methodological framework that focuses specifically on the retextualization of speech to writing, the author ends up disregarding the processes involved in productions from the written, to the written. Having this gap as a basis for reflection and thinking about activities built by children in a school environment, our initial discussion presents a theoretical-methodological framework that specifically covers aspects and procedures involved in the process of retextualization of written genres to written genres. The aim is to contribute both to the improvement of the state of the art and to enable a
\end{abstract}

${ }^{1}$ Trabalho financiado através de bolsa PNPD/Capes. 
more adequate methodological path in handling writing-writing retexting for the teacher/researcher.

KEYWORDS: retextualization; from writing to writing; text production; school activity.

\section{Situando a retextualização}

O processo de retextualização, conforme o consideraremos neste trabalho, é uma área relativamente nova dentro dos estudos textuaisdiscursivos - em especial na Linguística Textual; começa a ganhar espaço no início da década de 1990 - voltada à produção, refacção, reescrita e transformação de textos orais e escritos, seja dentro do ambiente pedagógico da sala de aula, seja em outro locus sócio-histórico-cultural em que a interação entre sujeitos possa ocorrer. Essa área foi adquirindo no Brasil uma série de interessantes trabalhos em múltiplos olhares (cf. DELL'ISOLA, 2007; DIKSON, 2017; DIKSON; MACIEL, 2015; HEBLING, 2009; MATENCIO, 2002; MARCUSCHI, 2001; VERCEZE; NOGUEIRA, 2005, dentre diversos outros), desenvolvidos em condições de produção históricas e interacionais diferentes, mas que dialogam entre si.

Acerca do assunto, em se tratando de investigações fora do país, quase não temos trabalhos específicos. O que podemos citar é o estudo realizado por Bilger e Teberosky (1991) com "adultos iletrados (illetrés) em processo de escolarização, para abordar justamente como se dá o processo de refacção através da reescritura de textos orais e escritos, considerando que este é um exercício que exige práticas específicas" (MACEDO, 2005, p. 59, grifo da autora). Elas investigam a manutenção dos aspectos linguísticos necessários para que se caracterize um gênero narrativo-informativo quando os adultos passam esse gênero da linguagem oral para a escrita, uma atividade de retextualização. Observam as estudiosas determinadas categorizações de elementos linguísticos na passagem do texto oral para o escrito, como a organização das informações, níveis sintáticos, tempos verbais adequados, verbos na voz passiva, nomes próprios, locativos, advérbios temporais, nível estilístico, dentre outros. Portanto, para as estudiosas, a retextualização seria, sinteticamente, a "transformação de um texto falado para um texto escrito" (MACEDO, 2005, p. 60). 
Por sua vez, no Brasil o termo retextualização apresentou-se a princípio através dos estudos de $\operatorname{Travaglia}^{2}$ (2003), sobretudo em sua tese de doutorado, que aborda o processo de tradução de uma língua para outra como uma retextualização, isto é, a produção de um novo texto a partir de um mesmo texto, que irá interagir dinamicamente com o leitor. Travaglia compreende que esse movimento não trata de "teorizar sobre tradução em termos de transporte de um sentido fixo de uma língua para outra, ou de decodificação" (p. 26), mas sim de retextualizar ou de re-enunciar: ao tratar o processo de tradução como uma atividade de retextualização, Travaglia propõe "uma abordagem da atividade tradutória mais diretamente pelo lado textual" (2003, p. 61), o que a leva a discutir preliminarmente o processo de criação de um texto, tendo como lugar de apoio a intenção comunicativa, seguida das etapas de planejamento, elaboração e, depois, revisão do texto produzido, chegando-se a um momento em que se considere satisfatória a tradução. Entende Travaglia essas operações de tradução - dentro das condições de produção do texto enquanto unidade discursiva de sentido como uma retextualização, processo que envolve

todos os elementos que conferem textualidade a um texto e que foram acionados pelo produtor do texto original, com a diferença de que, manejando uma outra língua, o tradutor estaria de certa forma manejando outros elementos ou até os mesmos elementos sob perspectivas diferentes. ([1993] 2003, p. 63)

Além da estudiosa, quando do gérmen do tema na década de 1990, também é possível identificar outros trabalhos dentro da perspectiva de retextualização, como o de Fiad e Mayrink-Sabinson (1991) em que apresentam termos como "refacção" e "reescrita", além do de Abaurre, Fiad e Sabinson (1995), que estudam os aspectos envolvidos em mudanças realizadas no interior de um texto durante uma escrita para outra de um mesmo texto. Outras pesquisas que vieram a surgir posteriormente sobre o assunto estão todas, sem exceção, marcadas pelo que consideramos ser o marco introdutório, formalizador teórico-metodológico e institucionalizador daquilo que hoje conhecemos como atividades de retextualização - trata-se da pesquisa proposta por Marcuschi (2001) quando da publicação do livro Da fala para a escrita: atividades de retextualização, no qual o autor aborda diversas

${ }^{2}$ A tese de Neusa Travaglia é de 1993, sendo publicada em 2003. 
perspectivas práticas e teóricas acerca da "oralidade" e do "letramento", da "fala" e da "escrita", perpassando por uma consistente discussão acerca da conceitualização da retextualização e dos processos que a envolvem durante a passagem do texto falado para o escrito.

Marcuschi (2001) apresenta discussões de cunho teóricometodológico, mais especificamente, como dito, voltadas às operações que ocorrem durante a passagem de textos orais para textos escritos: "Essa passagem ou transformação é uma das formas de realizar o que denomino retextualização" (p. 46). Embora esse termo já tenha sido anteriormente utilizado, conforme pontuamos, é Marcuschi quem lhe dá uma nova roupagem, inclusive viabilizando possibilidades inúmeras de alargamento para outras investigações que possam surgir.

Enquanto pesquisas anteriores discorrem sobre questões bem específicas de produção textual, oral ou escrita, e de reescrita, Marcuschi (2001) faz toda uma discussão dos aspectos das linguagens oral e escrita, mostrando que a retextualização pode ocorrer em quatro movimentos diferentes - falaescrita; fala-fala; escrita-fala; escrita-escrita-, o que inova os estudos do tema por mergulhar em outros vieses até então ainda não trilhados.

Marcuschi (2001), dessa forma, entende a retextualização enquanto processos e operações que ocorrem na passagem de um gênero textualdiscursivo de uma modalidade da língua para outra (da modalidade oral para a escrita, por exemplo), ou também uma passagem na mesma modalidade (do texto oral para outro oral, ou de escrito para escrito), o que é possível de um gênero para o mesmo gênero ou de um gênero para outro, independentemente da modalidade. A partir daí, cabe destacar que, para o autor,

A retextualização, tal como tratada neste ensaio, não é um processo mecânico, já que a passagem da fala para a escrita [da fala para a fala; da escrita para a fala; ou da escrita para a escrita $]^{3}$ não se dá naturalmente no plano dos processos de textualização. Trata-se de um processo que envolve operações complexas que interferem tanto no código como no sentido e evidenciam uma série de aspectos nem sempre bem-compreendidos. (2001, p. 46, grifo do autor)

A ideia é entendermos que, em qualquer que seja a atividade de retextualizar, vai haver extrema complexidade à sua realização e será necessária

${ }^{3}$ Acrescentamos tais expressões por entender que o raciocínio é absolutamente o mesmo. 
a ativação de uma série de processos (cognitivos, de compreensão, linguísticos, textuais, discursivos, etc.), conforme detalharemos um pouco mais adiante, sempre levando em consideração que - já que nosso foco recairá na discussão dos aspectos de retextualização de textos escritos a partir de outros textos escritos, principalmente enquanto atividades escolares - "uma retextualização implica que se leve em consideração as condições de produção, de circulação e de recepção dos textos" (DELL'ISOLA, 2007, p. 12).

Na mesma esteira de Marcuschi (2001), mas com um foco de discussão (assim como o nosso) voltado à produção partindo do texto escrito para o texto escrito, Dell'Isola vai dizer que

Por retextualização entende-se o processo de transformação de uma modalidade textual em outra, ou seja, trata-se de uma refacção e reescrita de um texto para outro, processo que envolve operações que evidenciam o funcionamento social da linguagem. (2007, p. 10)

A autora incorpora, com isso, uma definição de retexto agora voltada à escrita em sala de aula e, em especial, que demonstra o funcionamento e a importância social da linguagem produzida no ambiente escolar.

Entendendo, então, o movimento de retextualização escrita-escrita ${ }^{4}$ - a partir da conjuntura colocada - enquanto uma tarefa não apenas de transformar um texto-inicial escrito em um texto-final escrito por diversos fatores (cognitivos) em complexidade, que abordaremos mais adiante, bem como observando que todo contexto histórico e teórico-metodológico do assunto contém uma lacuna bem larga em se tratando de escrita-escrita (no que diz respeito à falta de discussão referente aos aspectos, processos e operações teórico-metodológicos da retextualização de gêneros escritos para gêneros escritos), propomos um ensaio inicial que busca refletir exatamente uma nova reconstrução ou ressignificação de ordem teórica e metodológica, a partir do que Marcuschi (2001) discute, no sentido de especificar operações e processos que são e estão envolvidos diretamente na retextualização de um gênero-base escrito para outro gênero-base escrito.

\footnotetext{
4 "Retextualização escrita-escrita" diz respeito à retextualização de um gênero-base escrito para um gênero-fim também escrito.
} 
Tendo como ponto de partida textos escritos por crianças em processo de alfabetização em ambiente escolar ${ }^{5}$ - o que também se configura como relevante tema para as investigações em Linguística Aplicada -, percorreremos uma trilha teórica de apresentação e reconstrução de alguns conceitos que perpassam a retextualização. Nesse sentido, propomos um caminho mais conciso e específico para a análise de textos, a partir de diversas operações cognitivas que permeiam e se infiltram no trato de manuscritos escolares produzidos por crianças em atividades em sala de aula, tendo como gênero-base um texto escrito e como gênero-fim também um texto escrito. A intenção maior é, se não sanar, pelo menos dirimir as dificuldades teórico-metodológicas que pesquisadores dessa área vêm deparando por conta da falta de categorias - tanto definidoras quanto de análise - dos processos que envolvem a retextualização escrita-escrita.

\section{Por mais aspectos envolvidos nos processos (cognitivos) da retextualização escrita-escrita}

Conforme apontamos, vamos considerar que, acerca do estado da arte, em especial do ponto de vista teórico-metodológico, temos praticamente uma pesquisa de consistente porte, a de Marcuschi (2001), a qual, poderíamos dizer, "funda" no Brasil as investigações de retextualização, especialmente sobre fala-escrita, como as conhecemos nos dias atuais. Partindo então dessa pesquisa e levando em consideração tanto o quadro intitulado "Aspectos envolvidos nos processos de retextualização” (MARCUSCHI, 2001, p. 69),

\footnotetext{
${ }^{5}$ Esta pesquisa é parte inicial da investigação que está sendo desenvolvida em estágio de pós-doutoramento no Programa de Pós-Graduação em Letras e Linguística da Universidade Federal de Alagoas (PPGLL/UFAL), sob supervisão do Prof. Dr. Luiz Fernando Gomes. O estudo envolveu um projeto didático em duas escolas públicas da cidade de Garanhuns (PE) (terceiro e quarto anos do ensino fundamental) voltado à produção de atividades de retextualização de um gênero escrito (cordel e fábula) para outro gênero escrito (quadrinhos). O corpus já se encontra em início de análise (no prelo), a partir da teoria que aqui estamos propondo. Não apresentaremos análises agora, apenas o caminho teórico-metodológico que vem sendo desenvolvido. Em breve um estudo mais completo será publicado.
} 
FIGURA 1 - Aspectos envolvidos nos processos de retextualização

\begin{tabular}{|c|c|c|c|}
\hline \multicolumn{3}{|c|}{ lingüísticos-textuais-discursivos } & cognitivos \\
\hline $\begin{array}{l}\text { (A) } \\
\text { idealização } \\
\text { eliminação } \\
\text { completude } \\
\text { regularização }\end{array}$ & $\begin{array}{c}\text { (B) } \\
\text { reformulação } \\
\text { acréscimo } \\
\text { substituição } \\
\text { reordenação }\end{array}$ & $\begin{array}{l}\text { (C) } \\
\text { adaptação } \\
\text { tratamento da } \\
\text { seqüência } \\
\text { dos turnos }\end{array}$ & $\begin{array}{c}\text { (D) } \\
\text { compreensão } \\
\text { inferência } \\
\text { inversão } \\
\text { generalização }\end{array}$ \\
\hline
\end{tabular}

Fonte: Marcuschi (2001, p. 69)

quanto toda a discussão traçada no referido estudo a partir desse quadro (Figura 1), sugerimos uma reconfiguração de tais aspectos debatidos por Marcuschi (2001, p. 69-125), a partir de um outro quadro teóricometodológico ${ }^{6}$ de características acadêmico-investigativas dentro dos aspectos e operações cognitivas envolvidas nos processos de retextualização, mais especificamente em atividades escolares que seguem na linha da passagem de um texto-base escrito para um texto-fim escrito (Quadro 1):

\footnotetext{
${ }^{6}$ Antes de mais nada, é de suma importância que fique bem claro que tal quadro dos aspectos envolvidos nos processos de retextualização escrita-escrita não se esgota nele mesmo; ou seja, o que apresentamos é uma proposta de possibilidades de processos e operações de natureza cognitivo-linguístico-textual-discursiva, a partir de observações e análises de atividades escolares em que os alunos possuem o papel de retextualizar determinado gênero escrito para outro determinado gênero escrito - o que significa dizer que outros aspectos e operações podem ocorrer, diferentes dos que aqui estamos propondo e discutindo, pois não podemos jamais desconsiderar a plasticidade social e fluida da língua escrita/falada em seus inúmeros contextos de (re)produção. Façamos nossas as palavras de Marcuschi (2001, p. 73): "É sempre temerário construir um modelo [o autor refere-se às operações textual-discursivas que propõe para análise da retextualização de textos falados para escritos]. Além disso, é perigoso, pois ele passa imediatamente a ser tomado como uma fórmula mais ou menos mágica que devemos produzir resultados tão logo seja aplicada". Portanto, não trazemos fórmula nesses aspectos, mas possibilidades de interpretação nas operações do retexto. Trata-se de uma sugestão, um ponto de partida, um princípio analítico teórico-metodológico dentro dos estudos de retextualização escrita-escrita, sempre aberto a rediscussões e reencaminhamentos.
} 
QUADRO 1 - Quadro escrita-escrita

ASPECTOS ENVOLVIDOS NOS PROCESSOS DE RETEXTUALIZAÇÃO ESCRITA-ESCRITA

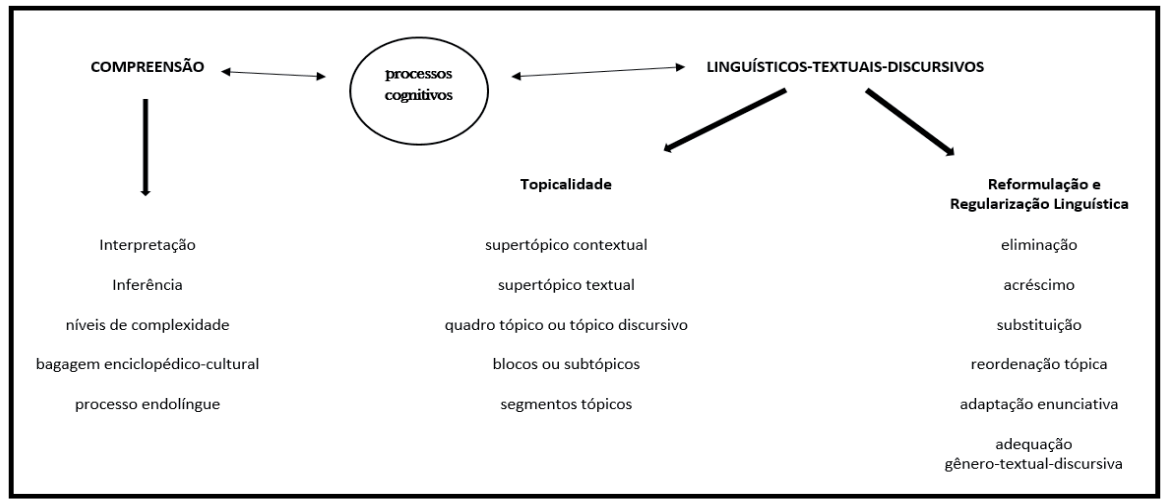

Observando o Quadro 1, em que propomos determinados aspectos envolvidos no processo de retextualização escrita-escrita, percebemos que os aspectos se subdividem em dois grandes movimentos, um denominado compreensão e outro direcionado aos níveis linguísticos-textuaisdiscursivos, ambos intercruzados pelos processos cognitivos. Dentro desses movimentos temos três blocos.

O primeiro está diretamente ligado às atividades cognitivas da compreensão, sendo composto por ações que culminam em interpretação, inferência, niveis de complexidade, bagagem enciclopédico-cultural e processo endolingue (com seus desdobramentos ${ }^{7}$ ).

O segundo liga-se às atividades cognitivas dos aspectos linguísticostextuais-discursivos, sendo representado pelas questões centrais da topicalidade. Esta, por sua vez, se desdobrando em supertópico contextual, supertópico textual, quadro tópico ou tópico discursivo, blocos ou subtópicos e segmentos tópicos.

O terceiro bloco, assim como o anterior, está relacionado aos processos linguísticos-textuais-discursivos, especificamente à reformulação e regularização linguística, com operações voltadas a processos de eliminação, acréscimo, substituição, reordenação tópica, adaptação enunciativa e adequação gênero-textual-discursiva.

\footnotetext{
${ }^{7}$ Entenda-se "desdobramentos" enquanto possibilidades outras de compreensão, além das que estão elencadas nesse bloco.
} 
Além desses três blocos insertos no processo escrita-escrita, é muito interessante e imprescindível ressaltar que os processos cognitivos estão presentes em absolutamente todos os movimentos dos blocos e em suas subdivisões, numa ligação de ida e vinda sem início, meio ou fim. Isso porque entendemos neste ensaio a cognição - especialmente no que concerne às atividades escolares envolvendo escritura/leitura/oralidade - como um processo ininterrupto e continum, o que nos faz acolher a tese de que é absolutamente impossível apreender questões da ordem da feitura e refeitura textuais (na modalidade escrita ou oral), dentro da compreensão ou do linguístico-textual-discursivo, excluindo-se os processos cognitivos, pois estes são inerentes a quaisquer capacidades ou atividades intelectuais e culturais do sujeito historicamente situado.

\section{Aspectos e procedimentos de compreensão na retextualização}

Dentre os aspectos envolvidos nos processos de retextualização escritaescrita, talvez a compreensão seja uma das mais caras para a produção do texto-fim com o máximo possível de sustentabilidade tópica em relação ao texto-base. Dito de outro modo, compreender o texto-base, tê-lo bem apreensível, entendê-lo dentro de parâmetros sócio-histórico-culturais, interpretativos, inferenciais e linguístico-textuais são ações indispensáveis para que a topicalidade durante a reformulação seja mantida, com as especificidades do gênero textual que será re-produzido ${ }^{8}$, retextualizado. Marcuschi, tomando a discussão sobre a compreensão, ressalta que:

\footnotetext{
${ }^{8}$ Enquanto no Dicionário Eletrônico Houaiss a "reprodução" é entendida como "imitação fiel, ato ou efeito de reproduzir-se, mostrar novamente, copiar, repetir-se..." - sempre no sentido de produzir da mesma forma algo que antes foi feito, sem mutabilidade, apenas com o intuito de repetir de novo a mesma coisa -, utilizamos aqui o termo re-produção, dentro do contexto de atividades de manuscritos escolares em sala de aula, enquanto sinonímia aproximada de retextualização, pois enxergamos o ato ou efeito de re-produzir textos orais/escritos como um novo processo de (re)escrita/(re)oralização de determinado gênero ou modalidade para outro gênero ou modalidade, dessa vez não com a intencionalidade de "repetir de novo a mesma coisa", mas de reconstruir um gênero textual a partir de outro. Dizendo de outra forma, a re-produção é um movimento de ação textual mutacional de gêneros, em que uma produção de texto já pronta é re-produzida, mantendo seus tópicos principais, em uma outra formatação social, em outro gênero, atitude de produzir um textofim a partir de um texto base, seja de um gênero para outro gênero ou de uma modalidade para outra modalidade, da mesma forma que a retextualização.
} 
as sérias questões concernentes a problemas de compreensão surgidos no processo de retextualização ainda estão por serem tratadas. Friso, no entanto, que toda atividade de retextualização implica uma interpretação prévia nada desprezível em suas consequências [...]. O problema maior se dá quando se passa de um gênero para outro, já que neste caso muda até mesmo o modelo global da transmissão. (2001, p. 70, grifos nossos)

Conforme se observa, a compreensão é uma questão séria - "nada desprezível"! - a ser tratada quando se fala em retextualização, tendo em vista que o problema maior parece ocorrer na re-produção de um gênero para outro gênero, exatamente o padrão de retexto por nós escolhido nas atividades escolares. Não compreender o texto-base implicaria, óbvia e necessariamente, problemas na escritura final dos manuscritos escolares, seja nas operações cognitivas de topicalidade ou nas de reformulação, dentro dos parâmetros linguísticos-textuais-discursivos, o que desencadearia, sem dúvida, falhas de sentido e significação do gênero-fim ${ }^{9}$. Por isso, é interessante entender, conforme ainda aponta Marcuschi, que

antes de qualquer atividade de transformação textual, ocorre uma atividade cognitiva denominada compreensão. Esta atividade, que em geral se ignora ou se dá por satisfeita e não problemática, pode ser a fonte de muitos problemas no plano da coerência no processo de retextualização. (2001, p. 47, grifos do autor)

Em rodapé, o autor ratifica: "O ato de produzir sentido a partir de um texto é um ato de compreendê-lo, e não de compreendê-lo bem. A boa compreensão de um texto é uma atividade particular e especial"' (2001, p. 70, grifos do autor). É interessante notar que a compreensão é uma atividade "particular e especial", entretanto, também não podemos negar que, no ambiente pedagógico de sala de aula, os textos não fazem "milagres" sozinhos - é absolutamente necessário que haja participação, intervenção, auxílio e orientação dos professores e das professoras.

Sem deixar de lado todas as outras possibilidades de compreensão que o vasto campo cognitivo humano suporta - e que não temos a intenção de abarcar e discutir, o que seria praticamente impossível -, conforme se observa o Quadro 1 nota-se algumas operações que entendemos

\footnotetext{
${ }^{9}$ gênero-fim = texto-fim; gênero-base $=$ texto-base .
} 
essenciais no trato preliminar do gênero-base para se ter um gênero-fim re-produzido a contento, com manutenções tópicas principais. Vejamos quais seriam esses processos e operações tão caros ao leitor/aluno para que o procedimento cognitivo de compreensão possa funcionar de tal maneira que a retextualização caminhe dentro do desejável, dentro da produção de sentidos e significações pertinentes.

(1) Interpretação: talvez seja o termo que mais ouvimos/falamos em ambiente escolar, especialmente no trato com texto/textualidade durante as aulas de língua portuguesa. Vamos apreendê-lo ${ }^{10}$, dentro das operações e processos cognitivos de compreensão do texto-base para efeito de retextualização escrita-escrita, enquanto um movimento de (i) apresentar possibilidades de significação; (ii) deslocar e estabelecer sentidos; (iii) explanar análises críticas patentes e subjacentes ao texto; (iv) entender e captar conhecimentos e pluralidades das múltiplas intenções possíveis ao texto; e $(v)$ exercer reflexão discursiva a respeito dos processos sóciohistórico-culturais que subjazem ao texto.

(2) Inferência: embora haja um limite bem tênue entre essa operação e a anterior - tendo em vista que se pode interpretar algo a partir de inferências ou inferir algo a partir de alguma interpretação -, vamos entendê-la como (i) um ato ou um efeito de deduzir algo por meio de raciocínio; (ii) possibilidade de ilação; e (iii) raciocínio concluído ou desenvolvido a partir de premissas e de indícios.

(3) Niveis de complexidade: essa operação dos aspectos cognitivos envolvidos nos procedimentos de compreensão tem relação direta com o textobase, no sentido de estabelecer o quão complexo é o gênero proposto para leitura/discussão. A complexidade opera no sentido de estabelecer (ou não) a coerência entre os componentes textual-discursivos que necessitam funcionar entre si, dentro de numerosas relações de interdependência, coordenação, subordinação e intergenerecidade dos textos nas conjunturas socioculturais humanas. Caso o professor

\footnotetext{
${ }^{10}$ Tanto essa quanto as demais operações dentro do aspecto da compreensão possuem diversas possibilidades de definição, de discussão, de entendimento. Não estamos esgotando elementos que comportem "interpretação" ou os demais processos; ao contrário, aqui abrimos o leque para que esses conceitos possam ser aprimorados, discutidos e melhorados por estudos posteriores. Este é apenas mais um ponto de partida nos estudos sobre escrita-escrita.
} 
leve ao ambiente escolar um gênero-base que possui um nível de complexidade além da série, da idade, do contexto social ou da amplitude escolar-cultural dos alunos, é muito provável que haja problemas de compreensão. A devida seleção de um gênero textual adequado à turma, aos alunos e à conjuntura social em que estão inseridos é uma ação docente de extrema valia para uma re-produção do texto-base significativa.

(4) Bagagem enciclopédico-cultural: como se observa, essas operações cognitivas dialogam entre sim e se estreitam de tal modo que delimitar o fim de uma e início da outra não é tarefa simples. Falar de bagagem enciclopédicocultural ${ }^{11}$ para fins de compreensão escrita-escrita seria tratar diretamente de técnicas, conteúdos, experiências sociais/escolares/culturais, relações e encadeamento de contextos históricos em que texto e leitor se inserem. Em uma palavra: seria todo conhecimento que adquirimos em nossa vida, nos mais plurais e diversos locus sócio-históricos com que possamos ter contato. Ou seja, a bagagem cultural do leitor (ou aluno, no nosso caso) é fator decisivo na compreensão ou não do texto-base - quanto mais bagagem o aluno carregar, melhor e mais consistente ficará o processo compreensivo do gênero textual levado à discussão.

(5) Processo endolingue: Marcuschi, tratando da importância da interpretação no processo de retextualização, afirma que nessa atividade há "uma espécie de tradução endolíngue que, como em toda tradução, tem uma complexidade muito grande" (2001, p. 70), acrescentando que o problema maior se dá quando se passa de um gênero para outro. $\mathrm{O}$ processo endolíngue, que aqui vamos tomar (no movimento escritaescrita) como uma forma de tradução dentro da própria língua, está diretamente ligado à condição de interpretação; isto é, quando há uma interpretação dentro do que a topicalidade permite, com concernência, vamos obter um processo de mão dupla: a capacidade cognitiva endolíngue precisa, então, perpassar o texto-base e o texto-fim. Dizendo de outra maneira: é necessária uma compreensão do texto-base que ative e encaminhe o leitor a uma interpretação cognitiva projetada ao texto-

\footnotetext{
${ }^{11}$ Podemos, sem problemas, fazer uma ponte com o "conhecimento de mundo" tratado por Kleiman, que "abrange desde o domínio que um físico tem sobre sua especialidade até o conhecimento de fatos como 'o gato é um mamífero', 'Angola está na África', 'não se deve guardar fruta verde na geladeira', ou 'na consulta médica geralmente há uma entrevista antes do exame físico"” (2004, p. 20-21).
} 
fim - ao ler, ao entender, ao compreender o texto-base, o leitor já inicia os procedimentos cognitivos voltados à tradução para o gênero que se pretende re-produzir, o gênero-fim. Essa ação, em processo endolíngue, estaria dessa maneira ligada diretamente ao texto-base e ao planejamento - mental, em rascunho, em discussão etc. -no que concerne à interpretação, e ao texto-fim situado no gênero proposto enquanto atividade escolar, a retextualização.

\section{A topicalidade em retextualização}

O segundo bloco do Quadro 1 diz respeito à topicalidade, a qual consideramos um dos aspectos centrais - se não o central - dentro dos processos da retextualização escrita-escrita. Vamos enxergar a topicalidade como "um princípio organizador do discurso" (LINS, 2008, p. 16). Discutiremos, então, o tema a partir de alguns pontos relevantes da topicalização textual, seguidos de processos e operações teórico-metodológicas que consideramos de suma relevância para a re-produção escrita-escrita, quais sejam: supertópico contextual, supertópico textual, quadro tópico ou tópico discursivo, blocos ou subtópicos e seguimentos tópicos.

Embora qualquer noção de tópico discursivo (TD), teoricamente falando, carregue uma complexidade ímpar em qualquer tentativa de "fatiálo”, entendemos, assim como Jubran et al. (1996), Fávero (1997), Koch et al. (1990) e outras pesquisas mais contemporâneas da Linguística Textual, que, didática e metodologicamente, subdividir na teoria os parâmetros de topicalidade se torna não só possível, mas também necessário, passível de análises e de aplicabilidade em investigações textual-discursivas, inclusive em sala de aula de retextualização.

Seria, portanto, a progressividade lógica, a contiguidade narrativa ou, como defendem Jubran et. al. (1996), Fávero (1997), Koch (2000), Lins (2008), Koch e Elias (2010), dentre outros, o "tópico discursivo", o que se constitui a partir de um continuum seja na fala, escrita, escrita-fala ou fala-escrita (em nosso caso, na escrita-escrita). Tem-se, então, a noção da topicalidade enquanto possiblidade operacionalizável de unidade de análise nos processos cognitivos linguísticos-textuais-discursivos.

Essa noção em funcionamento dentro do estatuto processual da produção de textos é o que esses autores apresentam enquanto tópico: " $\mathrm{Na}$ linguagem comum, tópico é, portanto, aquilo sobre o que se fala" 
(KOCH; ELIAS, 2010, p. 173, grifo das autoras). Sua importância (enquanto noção operacionalizável) se encontra na possibilidade de análises tanto textuais quanto (co)enunciativas, compreendendo alguns pontos que fazem o texto ganhar sentido, quer seja no papel quer seja na fala, na conversa.

Tendo o movimento de centrar-se em algum assunto (um dos aspectos mais marcantes da noção do tópico, da topicalidade) e levando em consideração as investigações pioneiras realizadas por Jubran et. al (1996) e Fávero (1997), e mais recentemente as de Koch (2000), de Koch e Elias (2010), dentre outras, vê-se duas propriedades que definem a categoria "tópico": a de centração e a de organicidade. Na propriedade de centração-que significa "falar-se de alguma coisa" (LINS, 2008, p. 15) - há os traços de

a) concernência: a relação de interdependência semântica entre os enunciados - implicativa, associativa, exemplificativa, ou de outra ordem - pela qual se dá sua integração no referido conjunto de referentes explícitos ou inferíveis; b) relevância: proeminência desse conjunto, decorrente da posição focal assumida pelos seus elementos; e c) pontualização: localização desse conjunto, tido como focal, em determinado momento da mensagem. (JUBRAN et al., 1996, p. 361-362, grifos nossos)

E na propriedade de organicidade vamos observar relações de

interdependência que se estabelecem simultaneamente em dois planos: hierárquico, conforme as dependências de super-ordenação e subordenação entre tópicos que se implicam pelo grau de abrangência do assunto; no plano sequencial, de acordo com as articulações intertópicas em termos de adjacências ou interposições na linha discursiva. (JUBRAN et. al., 1996, p. 361-2, grifos nossos)

Conforme apontam os autores, "Centração e organicidade são, em síntese, traços definidores de tópico, enquanto categoria abstrata, primitiva" (1996, p. 363). Fávero (1997, p. 46), tratando das questões de interdependência e hierarquização, afirma que é permitido "dizer que há níveis de estruturação dos tópicos, indo desde um constituinte mínimo, subtópico ( $\mathrm{SbT}$ ), até porções maiores, tópicos ( $\mathrm{T}$ ) ou supertópico $(\mathrm{ST})$, constituindo um Quadro Tópico" (grifos da autora). Com o fim de ilustrar a assertiva, Fávero (1997) apresenta um quadro relativo a tópico (Figura 2) e outro exemplificando uma análise conversacional realizada a partir desses princípios (Figura 3): 
FIGURA 2 - Estrutura do tópico

\section{QUADRO TÓPICO}

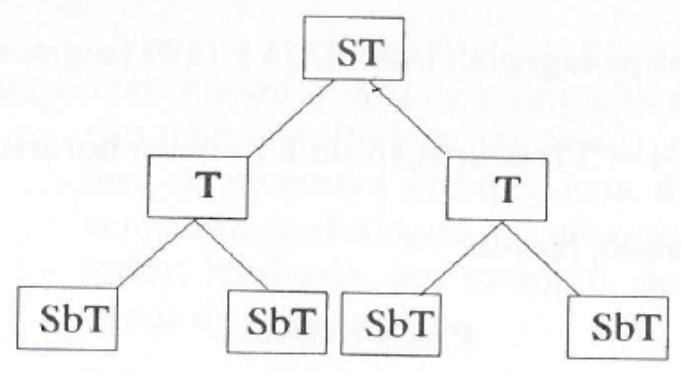

Fonte: Fávero (1997, p. 47)

FIGURA 3 - Esquema de uma análise dialogal ${ }^{12}$

Transpondo-se este esquema para o texto 1, obtém-se :

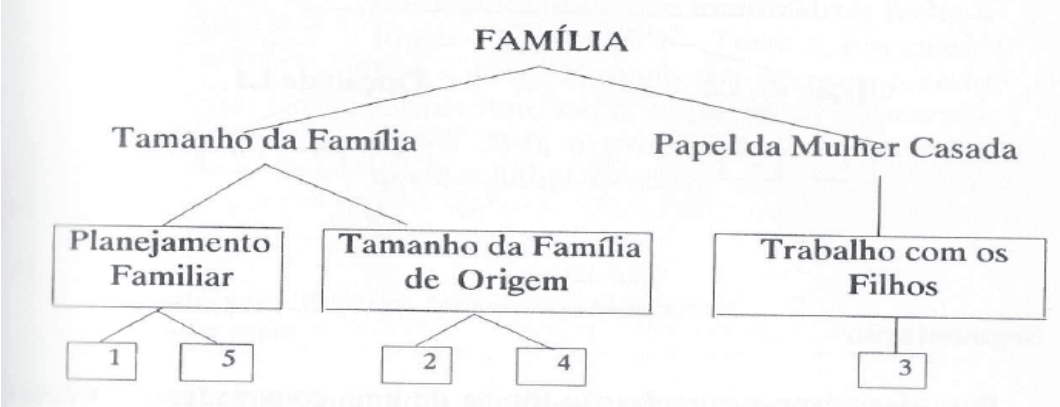

Fonte: Fávero (1997, p. 47)

Fávero vai um pouco mais além, defendendo que para descrever a organização tópica é necessário examinar a delimitação de segmentos tópicos (representados na Figura 3 pelos números 1, 5, 2, 4 e 3), definidos por ela enquanto "pequenas porções tópicas, com base no princípio de centração"

\footnotetext{
${ }^{12}$ Essa análise é realizada a partir de um diálogo do banco de dados do Projeto de Norma Urbana Oral Culta (Nurc), constante em Fávero (1997). A autora toma como supertópico "família", e como tópicos "tamanho da família" e "papel da mulher casada", enquanto subtópicos são "planejamento familiar", "tamanho da família de origem" e "trabalho com os filhos". Além disso, traz algumas operações, numeradas de 1 a 5 , que seriam os segmentos tópicos.
} 
(1997, p. 48). O tópico só existe, dessa maneira, porque os subtópicos e segmentos tópicos o formam. Um texto, portanto, compõe-se

de segmentos tópicos, direta ou indiretamente relacionados com o tema geral ou tópico discursivo. Um segmento tópico, quando introduzido, mantém-se em foco por um determinado tempo, após o qual, com ou sem intervalo de transição, vai ocorrer a introdução de um novo segmento tópico. (KOCH; ELIAS, 2010, p. 179, grifo das autoras)

Koch também mostra que "podemos denominar aos fragmentos de nível mais baixo de segmentos tópicos; um conjunto de segmentos tópicos formará um subtópico" (1992, p. 72, grifos nossos). Ou seja, as partículas da discursividade textual (escrita e oral) que se juntam para formar um princípio de sentido ou uma articulação pontual de compreensão - os segmentos tópicos que, em conjunto, formulam o subtópico - darão vida e sustentação ao tópico discursivo.

Dessa forma, apreendemos de Lins (2008), partindo dos trabalhos feitos por Goutsos (1996), que o tópico (junto com o subtópico) pode ser entendido teoricamente como uma estrutura que se opera organizadamente, e "não é definido e identificado como uma unidade a priori, mas como resultado de marcação de fronteiras” (GOUTSOS, 1996, apud LINS, 2008, p. 19). Eis a consistência e relevância dos subtópicos, delimitando a divisão dos sentidos com o intuito de aflorar uma compreensão tópica maior e principal. Dizendo de outra forma: a operação de feitura de sentido que o leitor/falante/escritor - na inter-relação - coloca em jogo só vai conseguir ser executada adequadamente e com uma compreensão plausível caso a marcação de fronteiras seja efetuada, para que as apreensões individuais e pontuais possam se colar de tal forma que um tópico maior venha a ser posto em relevo - momento em que se produz o sentido.

Levando em consideração essas delimitações e marcações fronteiriças, há dois procedimentos metodológicos de compreensão (que dialogam com toda a teoria trazida até aqui) e recorte discursivo para análises escrita-escrita, os quais entendemos bem pertinentes ao trato e às análises de retextualizações em manuscritos escolares. Esses procedimentos ocorrerão primeiro com o olhar mais apurado no texto-base, depois com a observação da manutenção (ou não) da topicalidade no texto-fim.

O primeiro é o trazido no trabalho de Lins (2008) que, ao analisar o tópico discursivo em tirinhas publicadas em jornais de grande circulação, 
formata uma (sub)divisão textual-discursiva para detalhamento de como os tópicos vão sendo construídos dentro dos quadrinhos progressivamente. A autora traz o supertópico como foco geral, mostrando como os quadros tópicos organizam-se dentro desse supertópico, e depois como os subtópicos vão se moldando em determinados assuntos para que os quadros tópicos ganhem forma. Como expediente exemplificativo, vejamos uma tirinha de O Menino Maluquinho, analisada por Lins (2008):

FIGURA 4 - Tira de O Menino Maluquinho

TIRA 192 O MENINO MALUQUINHO - Ziraldo 4/5/2001

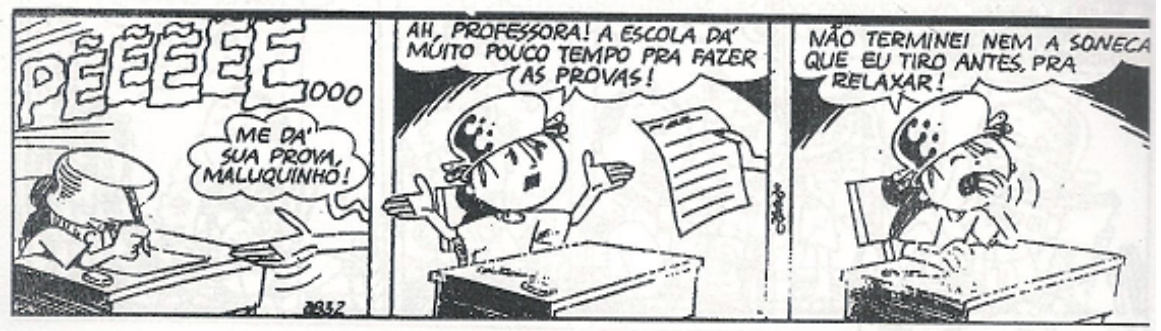

Fonte: Lins (2008, p. 134)

Lins (2008, p. 152-155), analisando diversas tirinhas de O Menino Maluquinho, apresenta algumas delimitações: “O Supertópico 'O Menino Maluquinho’ [...] desenvolve-se a partir de quatro quadros tópicos (Escola, Tecnologia, Relacionamento, Outros Interesses $\left.{ }^{13}\right)$ ". No quadro tópico "escola", que é exatamente o da tira aqui inserida, incluem-se os subtópicos "Tarefas", "Pouco tempo para provas" e "Soneca para relaxar". O esquema hierárquico, então, ficaria assim, segundo a autora: supertópico "Ser Menino Maluquinho é..."; quadro tópico ou tópico discursivo "Escola”; e subtópicos "Tarefas", "Pouco tempo para prova" e "Soneca para relaxar". Se porventura cada um desses quadros tópicos fosse discutido ou comentado, teríamos o desmembramento em subtópicos, depois em seus respectivos segmentos tópicos, e assim por diante.

\footnotetext{
${ }^{13}$ No caso da tirinha em questão, o quadro tópico ou tópico discursivo é “escola”, esses outros assuntos (tecnologia, relacionamento, outros interesses) dizem respeito a outras tirinhas de O Menino Maluquinho analisadas por Lins (2008).
} 
Outro traçado metodológico é o de Dikson (2015, p. 82), que analisa a referenciação e o tópico discursivo em histórias em quadrinhos inventadas por duplas de alunos recém-alfabetizados de segunda série do ensino fundamental (terceiro ano hoje), a partir de atividades semiestruturadas de histórias em quadrinhos retiradas do site da Turma da Mônica. Vejamos uma dessas delimitações tópicas a partir da atividade proposta com base na Figura 5:

FIGURA 5 - Atividade escolar forjada a partir de uma história em quadrinhos da Turma da Mônica
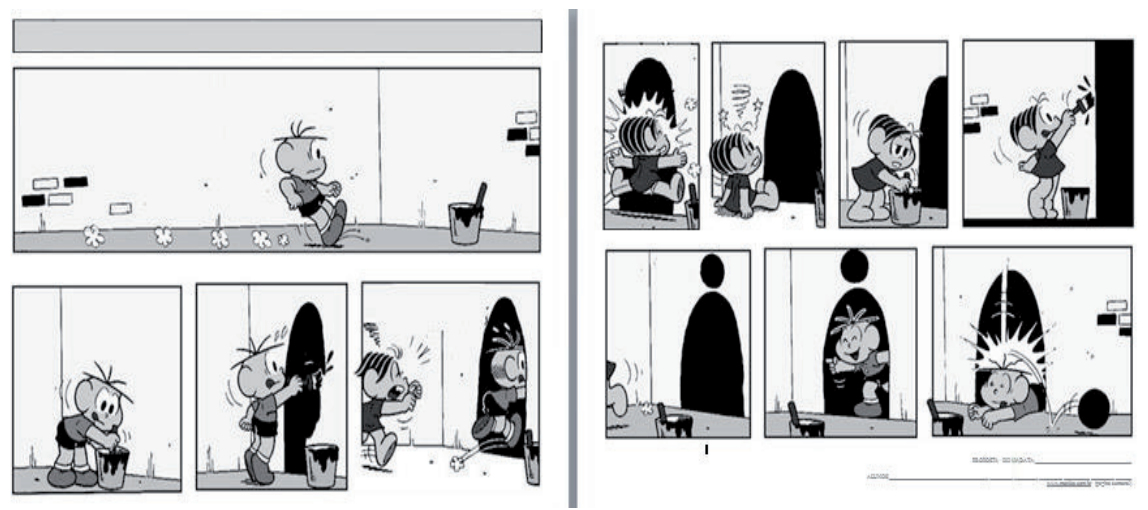

Fonte: Dikson (2015, p. 82$)^{14}$

Essa seria uma atividade de história em quadrinhos (HQ) da qual foram retiradas todas as marcas linguísticas para as crianças inventarem a história-textual. Nas análises, Dikson (2015) realizou o recorte da topicalidade do que a história poderia transparecer apenas através dessas imagens, para depois observar nos textos das crianças se conseguiriam manter em seus manuscritos toda estruturação referencial-tópica para construção do sentido que as imagens ofereceriam, ou seja, se o manuscrito escolar final traria uma história coerente. Acerca dessa atividade específica, assim o autor delimitou os tópicos para servirem de parâmetro às análises:

O supertópico que planeia a conjuntura desta HQ, considerando o ambiente escolar que o circunda e executa, poderia ser pensado como

\footnotetext{
${ }^{14}$ Imagem tratada pelo autor com o programa Paint para apagamento dos aspectos linguísticos, balões, falas e cores, transformando-se em atividade escolar.
} 
"construir um texto na tarefa escolar de HQ da TM", formado de um quadro tópico que perpassa por quatro blocos: num primeiro plano, "fugir de Mônica" e "pregar em peça em Mônica" (por Cebolinha); e, num segundo, "não deixar barato a fuga" e "fazer Cebolinha provar do próprio remédio, da tinta" (por Mônica). Ora, esse é o quadro tópicodiscursivo geral que faz essa HQ ter os estanques de sentido. O que importa, então, é saber se os processos referenciativos utilizados pela díade no texto foram determinantes para que esse quadro tópico seja assumido e assegurando dentro das características que o gênero requer (2015, p. 84, grifos nossos).

O que nos é importante observar nesses procedimentos de análise, demonstrados tanto por Lins (2008) quanto por Dikson (2015), é que essa operacionalização do discurso em textos escritos está diretamente ligada a uma estrutura tópica tanto das tirinhas quanto dos quadrinhos, situação essa que nos permite aplicar as metodologias desenvolvidas a partir do que Jubran et al. (1996) e Fávero (1997) discutem em qualquer texto falado ou escrito, como é o caso de atividades de retextualização em sala de aula.

Portanto, defendemos a tese de que, havendo uma delimitação estrutural - como fizeram Lins (2008) e Dikson (2015) - em qualquer que seja o texto-base, com tópicos recortados compreensivamente, a análise do texto-fim (o manuscrito escolar) a partir dos processos possíveis dentro dos aspectos de retextualização será muito mais consistente. Isso porque toda a delimitação da estrutura tópica do gênero-base vai abrir necessariamente um leque de interpretações acerca do gênero-fim, no sentido de analisar se este apresenta ou não os movimentos de topicalidade, com suas subdivisões; ou seja, trata-se de pensar se o sentido do texto final produzido vai ser ou não garantido a partir dos tópicos que compõem o texto inicial.

Conforme se nota, a topicalidade seria um campo-chave dentro desse processo de retextualizar um gênero escolar escrito para outro também escrito, abarcando, de acordo com o Quadro 1, cinco movimentos processuais cognitivos relativos aos aspectos linguísticos-textuais-discursivo:

(1) supertópico contextual: embora seja um termo inexistente nos estudos já elencados, vamos considerá-lo enquanto "supertópico" subdividido em dois (o contextual e o textual). O supertópico contextual seria a conjuntura do contexto que rodeia o processo de retextualizar e as condições de produção desses contornos, como a contextualização do ambiente da sala de aula no momento da atividade de re-produção. 
(2) supertópico textual: trata-se do "supertópico" propriamente dito dos textos-base e fim, se apresentando enquanto a grande ação textual, a centração da atividade de retextualizarar, a ação maior ou tema pontualizador da re-produção textual-discursiva, o conhecido acerca de.

(3) quadro tópico ou tópico discursivo: poderíamos considerá-lo o instante em que se inicia a subdivisão do supertópico, tendo em vista que o assunto/ tema principal que compõe o texto/discurso da atividade escolar não se apresenta de uma única vez ao leitor/aluno, mas vai sendo compreendido no conjunto de partes integrantes de um todo que faz sentido: essas partes são apresentadas em quadros tópicos ou tópicos discursivos principais.

(4) blocos tópicos ou subtópicos: como visto na discussão teórica, essas categorias não são fixas, mas “operacionalizáveis", a depender do corpus de análise do investigador e de todas as condições de produção do texto, oral ou escrito. Blocos tópicos ou subtópicos seriam passos de desmembramento ou divisão dos processos cognitivos de compreensão textual inseridos na topicalidade, ou seja, o quadro tópico ou tópico discursivo se desmembra em blocos ou subtópicos - quanto mais assuntos, temas ou centrações forem desenvolvidos no texto-discurso, mais fracionam-se os tópicos.

(5) segmentos tópicos: tidos como níveis mais "inferiores" da topicalidade, seriam os movimentos discursivo-textuais de mais baixa posição hierárquica, servindo de alicerce - no gênero-base enquanto estruturação cognitiva, e no gênero-fim enquanto manuscrito escolar - para a construção dos blocos, que por sua vez formulam os quadros, sendo estes os que montam o supertópico. Sempre vale lembrar que podemos operar tais categorias enquanto análises discursivas e que, na prática, apenas é possível observá-las a partir dos desmembramentos ocorrentes durante o reflexo escritural do texto-base ao texto-fim, o que significa dizer que apenas com o corpus em mãos é que se pode entender a topicalidade em funcionamento.

Apresentadas essas considerações, podemos asseverar que em processos de produção escolar de retextualização: (a) em relação ao gênero-base, é necessário que o aluno-leitor, após as devidas operações concernentes à compreensão do texto, planeje de que forma realizará o processo de retextualização, e isso só irá ocorrer porque será necessário 
aplicar - muitas vezes inconscientemente ${ }^{15}$ - as atividades cognitivas que implicam a topicalidade (do texto-base refletido no texto-fim) para que se vá montando e constituindo a produção dos sentidos antes mesmo de se iniciar a escritura da re-produção; e (b) em relação ao gênero-fim, trata-se de analisar no corpus, no manuscrito produzido, se os aspectos da compreensão, da reformulação e, em especial, da topicalidade, formatados a partir do gênero-base, foram ou não devidamente mantidos e se houve a construção dos sentidos objetivada na escrita-escrita.

Dessa maneira, sustentamos a hipótese, a partir do aparato teórico expendido e de análises de manuscritos finalizados, de que retextualizar um texto escrito para outro texto escrito, de um mesmo gênero ou de diferentes, não é possível sem levar em consideração as noções textuais-discursivas relativas a tópico discursivo, seja no aspecto cognitivo de compreensão global do texto-base - que já ocorre antes da ação de retexto -, seja no processo da retextualização, no movimento de escritura do novo texto.

\section{Reformulação e regularização linguística na retextualização}

Chegamos ao último bloco constante do Quadro 1, que trata dos processos linguísticos-textuais-discursivos voltados às operações cognitivas de reformulação e regularização linguística. Como se observou, enquanto os pontos referentes à compreensão estão mais ligados ao texto-base - que se refletirão (ou não) no texto-fim -, e os referentes à topicalidade possuem uma bifurcação ida-vinda por seu caráter de ativação cognitiva para processar o gênero-base em suas subdivisões tópicas, construindo-se o gênero-fim com a mantença (ou não) desses tópicos discursivos previamente apreendidos, as operações de reformulação e regularização linguista - em diálogo intercruzado com a compreensão e o tópico - estão mais diretamente relacionadas à realização prática e ativa da produção textual, da escritura, dos movimentos de re-produzir o texto-fim a partir do texto-base. Ou seja, são os processos práticos da retextualização escrita-escrita solicitada em sala de aula e formalizada através de atividades em manuscritos escolares.

Vamos entender, então, que tais processos e procedimentos referentes à reformulação só podem ser realizados em harmonia interativa com

${ }^{15}$ Entenda-se "inconscientemente" como uma ação meio que "automática". 
o princípio básico de regularização linguística. Não há como aplicar operações textuais-discursivas de reformular o que se lê/escreve durante uma atividade escolar sem que haja tentativas constantes de regularizar as formas linguísticas pertinentes ao gênero proposto na re-produção. Conforme pontua Dell'Isola, com quem concordamos,

O texto não será refeito pelo autor do original, por isso, estabeleceuse que, no processo de retextualização, seja respeitado o conteúdo do original e que não sejam feitas muitas mudanças, embora possam ser feitas intervenções quando o gênero exigir. Por isso, é importante considerar a configuração de cada gênero, pois estamos diante de uma transformação de um gênero textual escrito em outro gênero textual escrito. Em certos casos, algumas formas linguísticas são eliminadas e outras introduحidas; algumas são substituidas e outras reordenadas. Nesse processo de reescrita são feitas alterações regidas por estratégias de regularização linguística. (2007, p. 43, grifos nossos)

Ora, como se vê, o conteúdo original do texto-base deve ser respeitado, embora, dependendo do gênero proposto como texto-fim, intervenções e mudanças venham a ocorrer. Mas em todos os casos, sem exceção, quando se trata de escrita-escrita em ambiente pedagógico, inevitavelmente formas linguísticas serão modificadas, reordenadas, retiradas, acrescidas etc., e todas essas mudanças cognitivas de ordem textual-discursivas só podem ser realizadas através de estratégias de regularização.

Vamos entender, então, essas operações de regularização linguística enquanto processos de produção de sentidos permeados por ações que sempre procuram normalizar e normatizar o texto re-produzido, quer dizer, torná-lo regular, colocá-lo em ordem, fazê-lo viável, a partir de outro; em uma palavra: para constituir o processo de regularização linguística é absolutamente evidente a necessidade de reformular diversos parâmetros linguísticos-textuais-discursivos, tendo como ponto de partida um gênero textual escrito e como parâmetro final, outro gênero textual escrito. Para tal, sem desconsiderar quaisquer outros aspectos cognitivos textuais-discursivos que possam ocorrer, destrinchamos esse bloco em seis operações de suma relevância, conforme indicado no Quadro 1.

(1) eliminação: operação que consiste em retirar termos linguísticostextuais- discursivos presentes no gênero-base, apagando no texto-fim determinadas expressões, trechos, termos, frases, blocos de sentido, 
signos semióticos ${ }^{16}$, parágrafos ou segmentos tópicos. Essas ações muitas vezes são necessárias tendo em vista tanto a compreensão do texto-base quanto a formatação linguístico-textual do gênero-fim que se encontra em processo de retextualização.

(2) acréscimo: ação que caminha no sentido de incluir, implementar, inserir, adicionar ou introduzir termos linguísticos-textuais-discursivos no gênero-fim, acrescentando expressões, trechos, termos, frases, blocos de sentido, signos semióticos, parágrafos ou segmentos tópicos que não constavam do texto-base. Tais ações, da mesma maneira que a eliminação, são necessárias à construção do formato linguístico-textual do texto-fim.

(3) substituição: desdobra-se em operações textuais-discursivas que consistem em trocar, mudar/modificar por outro ${ }^{17}$, transformar em outro, permutar, remanejar, comutar, do texto-base para o texto-fim, expressões, trechos, termos, frases, blocos de sentido, signos semióticos, parágrafos ou segmentos tópicos, sempre observando as ações pertinentes no movimento de re-produção de um texto para o outro.

(4) reordenação tópica: diz respeito a operações cognitivas de trato da topicalização, ou seja, no texto-base o gênero vai se apresentar com determinada produção de sentido - normalmente com início, meio e fim, ou mesmo em ordem diferente, mas com significado identificável, assegurando determinada sequencialização - e geralmente formatado em uma organização linearizada tópica, dentro de categorias fundantes para estruturação textual (supertópico textual, quadro tópico ou tópico discursivo, blocos ou subtópicos e segmentos tópicos, não necessariamente todas). $\mathrm{Na}$ produção do gênero-fim, durante o processo de retextualização, o autor/aluno pode ou não manter a disposição e organização tópica do texto-base. Mantendo-se essa estrutura, poderão ocorrer estanques de reordenação da topicalidade, a depender das propriedades estruturais dos gêneros base e fim e dos processos de compreensão do texto-base e de produção do manuscrito final. Por outro lado, modificando a estruturação da topicalidade do texto-base, acarretar-se-á uma reordenação

\footnotetext{
${ }^{16}$ Nos referimos mais especificamente a imagens que podem aparecer ou fazer parte da estrutura textual-discursiva de diversos gêneros escritos.

${ }^{17}$ Essa ideia remete a algo que já está no texto-base e, no texto-fim, é substituído por outro termo, podendo gerar polissemia, desde que ligado aos tópicos sustentatórios do gênero-base.
} 
de determinados blocos de sentidos, trechos ou segmentos, sempre a depender das propriedades mantenedoras necessárias ao sentido do gênero que se está escrevendo na re-produção, o texto-fim.

(5) adaptação enunciativa: como se sabe, boa parte dos gêneros textuais trabalhados em sala de aula do ensino básico possui estruturas narrativas, perpassando por personagens, espaços, tempos, diálogos, entre outras características. É, então, necessário, quando do trato desse tipo de texto, que o aluno/escrevente utilize dos mais variados recursos linguísticostextuais-discursivos para ajustar as formatações do texto-base, em especial as narrativas-dialogadas, ao que é possível dentro das estruturas do texto-fim. Enquanto Marcuschi (2001), tratando da retextualização fala-escrita, apresenta um bloco específico chamado "adaptação tratamento de sequência de turnos" (p. 69), vamos entender esse bloco na escrita-escrita como uma operação cognitiva do aluno para adaptar enunciativamente diálogos, vozes e discursos reportados de um gênerobase escrito para um gênero-fim também escrito, sempre a depender dos recursos linguístico-textuais que o texto-final vai comportar e suportar.

(6) adequaşão gênero-textual-discursiva: essa é uma operação que está diretamente ligada ao professor, especificamente ao modo como vai trabalhar, planejar e introduzir o gênero-base e o gênero-fim na sala de aula. Tratase de como irá discuti-los, dialogá-los, oralizá-los, construir atividades e refletir sobre os aspectos e estruturas de sentido textuais-discursivos neles presentes. Esse processo de imersão textual é exatamente o lugar de possibilidades para que o aluno realize a adequação gênero-textualdiscursiva, isto é, se o professor trabalha um conto como texto-base e solicita a re-producão dele em uma poesia, ou se apresenta como base uma notícia e requer uma retextualização em quadrinhos, só será possível adequar os gêneros se houver um trabalho significativo e consistente na sala de aula acerca de leitura/escrita/oralização/atividades do conto, da poesia, da notícia e dos quadrinhos, para o aluno ter a possibilidade de compreender o textobase e de construir o texto-fim, realizando a adequação a contento; caso contrário, os objetivos podem não ser alcançados.

\section{Considerações finais}

Esta discussão consistiu em um ensaio preliminar - de cunho exclusivamente teórico e metodológico - sobre aspectos e operações envolvidas nos processos de retextualização escrita-escrita, especialmente a partir 
de atividades em sala de aula. Tendo como parâmetros as investigações da área, sobretudo as forjadas, elencadas e rigorosamente discutidas por Marcuschi (2001) acerca da fala-escrita, propusemos um olhar específico para uma lacuna científico-acadêmica que vinha persistindo entre as questões teóricas e aplicações metodológicas da retextualização de um texto escrito para outro.

Entendemos, então, o movimento de retextualização escrita-escrita como um processo cognitivo que necessita indubitavelmente caminhar pela compreensão do texto-base para produzir um texto-fim adequado, evitando-se problemas de entendimento; pela estruturação da topicalidade do gênero-base, com o intuito de conhecer a arquitetura discursiva deste para que os tópicos discursivos principais e essenciais sejam devidamente assegurados no processo de produção do texto final, mantendo-se o sentido; e pelos movimentos cognitivos da regularização e reformulação linguísticas, para que o gênero final re-produzido possa carregar - textual e discursivamente - a compreensão e os tópicos principais do texto-base, constituindo, assim, a retextualização dentro dos parâmetros esperados em atividades realizadas em sala de aula.

Como explicado, não trouxemos análises de manuscritos escolares produzidos a partir de atividades de retextualização, tendo em vista que o objetivo específico aqui foi apresentar a reformulação do corpo teórico discutido. Além disso, a pesquisa ainda se encontra em execução, e em breve os resultados finais, com análise do corpus a partir do aparato teóricometodológico aqui discutido, serão devidamente publicados.

Por fim, esperamos que a pesquisa em tela (e ainda em andamento) possa implementar melhorias significativas ao estado da arte dentro das ciências da linguagem, especificamente no que concerne à Linguística Textual, a partir do campo teórico das investigações sobre retextualização escrita-escrita em atividades escolares, levando em consideração uma nova roupagem que foi discutida e detalhada com um quadro de categorias de análises que pode, sem dúvida, auxiliar e guiar professores/pesquisadores a um melhor entendimento de como o processo da re-produção ocorre em manuscritos produzidos em sala de aula, como se processa cognitivamente e como o viés metodológico e de investigação podem ganhar forma. 


\section{Referências}

ABAURRE, M. B. M.; FIAD, R. S.; MAYRINK-SABINSON, M. L. T. Considerações sobre a utilização de um paradigma indiciário na análise de episódios de refacção textual. Trabalhos de Linguística Aplicada, Campinas, v. 25, p. 5-23, jan./ jun. 1995. Disponível em: <https://goo.gl/J5FKVn>. Acesso em: 5 maio 2018.

BILGER, M.; TEBEROSKY, A. La connaissance de l'écrit chez les adultes “illetrés”. In: MARTY, N. (Coord.). Études de Linguistique Appliqueé: l'écrit dans l'oral. Paris: Didier Erudition, v. 81, p. 49-55, janv./mars 1991.

DELL'ISOLA, R. L. P. Retextualização de gêneros escritos. Rio de Janeiro: Lucerna, 2007.

DIKSON, D. A gênese da referenciação-tópica em processos de escritura de histórias em quadrinhos da Turma da Mônica: criação textual de alunas recém-alfabetizadas. 2015. 157 f. Tese (Doutorado em Linguística) - Universidade Federal de Alagoas, Maceió, 2015.

DIKSON, D. A retextualização enquanto processo de escritura e apropriação de gêneros textuais. Caminhos em Linguística Aplicada, Taubaté, v. 16, n. 1, p. 90-109, 2017. Disponível em: <https://goo.gl/3PdjMK>. Acesso em: 10 maio 2018.

DIKSON, D.; MACIEL, W. G. T. Processo de retextualização em sala de aula: um caminho de apropriação na escritura de gêneros textuais. Diálogos, v. 1, p. 605-615, 2015.

FÁvERO, L. L. O tópico discursivo. In: PRETI, D. (Org.). Análise de textos orais. 3. ed. São Paulo: Humanitas, 1997. p. 33-54.

FIAD, R. S.; MAYRINK-SABINSON, M. L. T. A escrita como trabalho. In.: MARTINS, M. H. (Org.). Questões de linguagem. São Paulo: Contexto, 1991. p. 54-63.

GOUTSOS, D. Modeling discourse topic: sequential relations and strategies in expository text. Norwood, NJ: Ablex, 1996.

HEBLING, C. B. Atividades de reformulação na conversação entre afásicos e não-afásicos. 2009. 116 f. Dissertação (Mestrado em Linguística) - Universidade Estadual de Campinas, 2009.

JUBRAN, C. C. A. S. et al. Organização tópica da conversação. In: ILARI, R. (Org.). Gramática do Português Falado. v. 2. Campinas: Editora da Unicamp, 1996. p. 357-397.

KLEIMAN, A. Texto e leitor: aspectos cognitivos da leitura. 9. ed. Campinas: Pontes, 2004.

KOCH, I. G. V. A inter-ação pela linguagem. São Paulo: Contexto, 1992. 
KOCH, I. G. V. O texto e a construção dos sentidos. São Paulo: Contexto, 2000.

KOCH, I.; ELIAS, V. M. Ler e compreender os sentidos do texto. 3. ed. 3. reimp. São Paulo: Contexto, 2010.

$\mathrm{KOCH}$, I. et al. Aspectos do processamento do fluxo de informação no discurso oral dialogado. In: CASTILHO, A. T. (Org.). Gramática do português falado. v. 1. Campinas: Editora da Unicamp, 1990.

LINS, M. P. P. O tópico discursivo em textos de quadrinhos. Vitória: Edufes, 2008.

MACEDO, H. O. O processo de refacção textual na linguagem escrita de sujeitos afásicos. 2005. 227 f. Tese (Doutorado em Linguística) - Universidade Estadual de Campinas, Campinas, 2005. Disponível em: <https://goo.gl/VJL4Tg>. Acesso em: 10 maio 2018.

MATENCIO, M. L. M. Atividades de (re)textualização em práticas acadêmicas: um estudo do resumo. Scripta, Belo Horizonte, v. 6, n. 11, p. 109-122, 2. sem. 2002. Disponível em: < https://goo.gl/XpkJng>. Acesso em: 10 maio 2018.

MARCUSCHI, L. A. Da fala para a escrita: atividades de retextualização. São Paulo: Cortez, 2001.

TRAVAGLIA, N. G. Tradução retextualização: a tradução numa perspectiva textual. Uberlândia: Edufu, 2003.

VERCEZE, R. M. A. N.; NOGUEIRA, E. S. Fala versus escrita: atividades de retextualização. Zona de Impacto, Rio de Janeiro: IBCT, v. 4, ano 8, nov. 2005. Disponível em: <https://goo.gl/8shw4j>. Acesso em: 10 maio 2018.

Data de submissão: 23/01/2018. Data de aprovação: 17/04/2018. 
No artigo "A retextualização escrita-escrita", com número de DOI: 10.1590/19846398201813068, publicado no periódico Revista Brasileira de Linguística Aplicada, vol. 18, n. 3, p. 503-529, na nota de rodapé 14, página 520:

Onde se lia:

Imagem tratada pelo autor com o programa Paint para apagamento dos aspectos linguísticos, balões, falas e cores, transformando-se em atividade escolar.

Leia-se:

Imagem tratada pelo autor com o programa Paint para apagamento dos aspectos linguísticos, balões, falas e cores, transformando-se em atividade escolar. Todas as atividades utilizadas no projeto didático em Dikson (2015), fazem parte do acervo "Práticas de Textualização na Escola", pertencente ao Grupo de Pesquisa L'AME (Laboratório do Manuscrito Escolar - PPGE/PPGLL-UFAL), sob coordenação do Prof. Dr. Eduardo Calil de Oliveira. 